\title{
Finite Element Analysis of Micro End Mill and Simulation of Burr Formation in Machining a Review
}

\author{
Aman Singhai', H. S. Sahu² \\ ${ }^{1}$ Research Scholar, ${ }^{2}$ Assistant Professor \\ Department of Mechanical Engineering, Millennium Institute of Technology, \\ Bhopal, Madhya Pradesh, India
}

\begin{abstract}
The recent technological progressions in industries have offered ascent to the continually growing requests for microstructures, sensors, and parts. Micro-milling is a promising method to create these scaled down structures, sensors, and parts. Yet, micro-milling still confronts some significant difficulties, tormenting further provision of this innovation. The most noticeable around them is micro burr formation. Burrs created along the completed edges and surfaces in micro-milling operation have huge effect on the surface quality and performance of the completed parts and microstructures. In any case, deburring of micro-parts is not conceivable because of bad accessibility and tight tolerances in micro segments. One of the methods to minimize micro burr formation in micro milling is by enhancing the geometry of the device. As minimization of micro burrs still remains a key test in micro machining, not many researchers have worked in this field. The main aim of the research work is to present finite element analysis of flat end mill micro cutters used in micro milling by varying geometry of the tools. Apart from this, study has been done in detail on burr formation in micro milling and what factors affect it. Burr formation simulation has been carried out while varying the tool geometry.
\end{abstract}

KEYWORDS: Burr formation, Two flute, Four flute, Tool geometry

\section{INTRODUCTION}

The fabrication of a wide variety of parts and products in various fields, like aeronautics, automotives, biomedical, medical and electronics requires proper finishing for proper mating and functioning of products. A variety of operations like milling, drilling, turning, grinding, EDM and water jet cutting are utilised to fabricate and finish parts. One of the most common and important form of machining is the milling operation, in which material is cut away from the work piece in the form of small chips by feeding it into a rotating cutter to create the desired shape. Milling is typically used to produce parts that are not axially symmetric and have multiple features, such as holes, slots, pockets, and even three dimensional surface contours. Contoured surfaces, which include rack and circular gears, spheres, helical, ratchets, sprockets, cams, and other shapes, can be readily cut by using milling operation. Recently, micro milling process has gained immense popularity due to market requirements and technological advancements which has lead to fabrication and use of micro structures. It possesses several advantages like ease of use, capability to produce complex three dimensional geometries, process flexibility, low set-up cost, wide range of machinable materials and high material removal rates. With the growth in technology, the expectations from products have greatly increased. More and more complex shaped parts of varying sizes are being designed, developed and used for a wide variety of industrial applications. The commercial success of a new product is strongly influenced by the highest possible quality and productivity achieved. This can be achieved only when the parts and/or products have excellent surface finish.

One of the important causes of poor surface finish is the formation of burrs along the machined edges boundaries. The impact of burr formation on the surface finish of microstructures is much more significant than in case of macrostructures because of comparable sizes of burrs and the parts formed during micro machining. Deburring in this case is expensive, and sometimes impossible, and, hence, the only solution is to minimise the formation of burrs.

To realize any surface accurately using conventional subtractive machining process, two most important factors to be properly controlled are: geometry of the cutting tool and the kinematic structure of the machine tool.

The cutting tool geometry along with the relative motion between the cutting tool and the work piece generates the profile of the cut. Even the shapes not possible to manufacture earlier are achievable due to increasedcontrol of machine tools by CNC controllers. Optimising the cutting tool geometry or the machining parameters or both, can help in the control of burr formation in micro machining.

\section{LITERATURE REVIEW:}

There are some papers which have been studied and referred on my work.

Min and Dornfeld burr formation has eight basic stages. The process starts with the continuous cutting stage in which burr formation is unaffected by the deformation and stress distribution, as long as the workpiece edge does not affect it. In the pre-initiation stage, the workpiece edge bends due to elastic deformation and a plastic deformation zone is formed around the primary shear zone.

Chern found that burrs formed in milling are dependent on the in-plane exit angle and classified burrs formed into five categories - the knife-type burr, the wave type burr, the curltype burr, the edge breakout, and the secondary burr. 
Gillespie classified four types of burrs based on formation mechanism - Tear, Rollover, Poisson and Cut-off burrs. A tear burr is the consequence of material tearing detached from the workpiece as opposed to shearing. The rollover burr is basically a chip that is bowed as opposed to sheared, bringing about a nearly bigger burr. This kind of burr is otherwise called a passageway burr in light of the fact that it is typically framed at the end of a cut in face-processing. The Poisson burr is an aftereffect of a material's tendency to lump at the sides when it is compacted until perpetual plastic deformation happens. It is like the burr shaped in punching operations. The cut-off burr is the consequence of workpiece partition from the crude material before the detachment cut is done.

Lee et al. In traditional courses of action, these top or entrance type burrs are generously more diminutive than exit type burrs, and typically no deburring procedure is important. Then again, micro-top or entrance type burrs are large comparatively in light of the fact that the cutting edge radius is substantially large as compared to the feed per tooth.

Li et al. The tools can even break if the cutting conditions are not chosen likewise. Subsequently, an exact estimation of the cutting powers of micro-end-milling assumes an essential part in controlling the determination of cutting conditions with a specific end goal to monetarily acquire high machining quality and guarantee as long an tool life as could be expected under the circumstances. At micro level, we can't accept that edge radius has unimportant impacts on cutting powers.

Weuleet al discovered that the roundness of a forefront is more critical at micro scale machining. As the span of an instrument decreases, the sharpness of the gadget can't be upgraded moderately due to stipulations in the mechanical assembly creation strategies and reduction in the structural nature of the instrument. Along these lines, the feed per tooth in micro-processing may be for all intents and purpose indistinguishable.

Kimet al tentatively confirmed that when the feed per tooth is practically identical with the edge radius of the apparatus, as is frequently the case in micro-milling courses of action, the chip shaping methodology gets discontinuous and the accepted comprehension that a chip is framed with each tooth pass is no more legitimate. As indicated by their model, the base chip thickness of different consolidations of devices and work piece materials may be evaluated focused around effortlessly achievable cutting force information.

\section{METHOD USED}

The investigation of the progress of cutting forces in any machining methodology is profoundly key for fitting, arranging and control of machining process and for the enhancement of the cutting conditions to minimize production expenses and times. Cutting force analysis assumes an imperative part in study of the different qualities of a machining process, viz. the dynamic stability, situating precision of the instrument as for the work piece, harshness of the machined surface and structure mistakes of the machined component, and so on.
In most micro-end-processing operations, the micro cutting device measurement differs from $0.1 \mathrm{~mm}$ to $1 \mathrm{~mm}$, and anxiety variety on the modest shaft of the micro cutting apparatus is much higher than that on an expected scale instrument, which definitely abbreviates the instrument's life. The tools can even break if the cutting conditions are not chosen likewise. Subsequently, an exact estimation of the cutting powers of micro-end-milling assumes an essential part in controlling the determination of cutting conditions with a specific end goal to monetarily acquire high machining quality and guarantee as long an tool life as could be expected under the circumstances. The roundness of a forefront is more critical at micro scale machining. As the span of an instrument decreases, the sharpness of the gadget can't be upgraded moderately due to stipulations in the mechanical assembly creation strategies and reduction in the structural nature of the instrument. Along these lines, the feed per tooth in micro-processing may be for all intents and purpose indistinguishable.

\section{CONCLUSIONS}

This thesis may concludes the technical sum-up of the thesis work on three-dimensional geometric modeling and analysis of micro end milling cutters and simulation of micro burrs formed during micro milling of Al6061-T6 alloy by using a tungsten carbide two flute micro end mill cutter. This is followed by directions for future work.

Burr formation is a major hindrance to good surface finish in case of both macro and micro milling. However, burr formation in case of micro milling is of greater importance than in case of conventional milling as burrs formed in the former case are of sub-micrometer size and deburring processes are expensive, and sometimes impossible. Hence, burr minimization is the only way of obtaining good surface finish in microstructures.To minimize formation of burrs in case of micro milling, either the cutting conditions or the tool geometry can be optimized. In this work, tool geometry optimization has been tried to be achieved by performing FE analysis on tools with different sets of rake and relief angles, for both two flute and four flute micro end mills.

\section{REFERENCES}

[1] Afazov, S.M., Ratchev, S.M. and Segal, J., Modelling and simulation of micro-milling cutting forces, Journal of Materials Processing Technology, Vol.210, pp. 21542162 (2010).

[2] Alrabii SA, An experimental study of burr formation in drilling and slot-end milling operations, Journal of Engineering, 15(4) (2009) 4219- 4240.

[3] Ávila M, Gardner J, Reich-Weiser C, Tripathi S, Vijayaraghavan A, Dornfeld D. Strategies for Burr Minimization and Cleanability in Aerospace and Automotive Manufacturing. SAE Transactions Journal of Aerospace, 114 (1), pp. 1073-1082 (2006).

[4] Aziz M, Ohnishi O, Onikura H, Innovative micro hole machining with minimum burr formation by the use of newly developed micro compound tool, Journal of Manufacturing Processes, 14 (2012) 224-232.

[5] Bao WY, Tansel IN, Modeling micro-end-milling operations. Part I: analytical cutting force model, International Journal of Machine Tools \& Manufacture, 40 (2000) 2155-2173. 
[6] Bao WY, Tansel IN, Modeling micro-end-milling operations. Part II: tool run-out, International Journal of Machine Tools \& Manufacture, 40 (2000) 21752192.

[7] Chang SSF, Bone GM, Burr height model for vibration assisted drilling of aluminum 6061-T6, Precision Engineering, 34 (2010) 369-375.
[8] Chen MJ, Ni HB, Wang ZJ, Jiang Y, Research on the modeling of burr formation process in micro-ball end milling operation on $\mathrm{Ti}-6 \mathrm{Al}-4 \mathrm{~V}$, International Journal of Advanced Manufacturing Technology, 62 (2012) 901-912.

[9] Chern GL, Analysis of Burr Formation and Breakout in Metal Cutting, Ph.D. Thesis, University of California at Berkeley, Berkeley, CA, (1993).

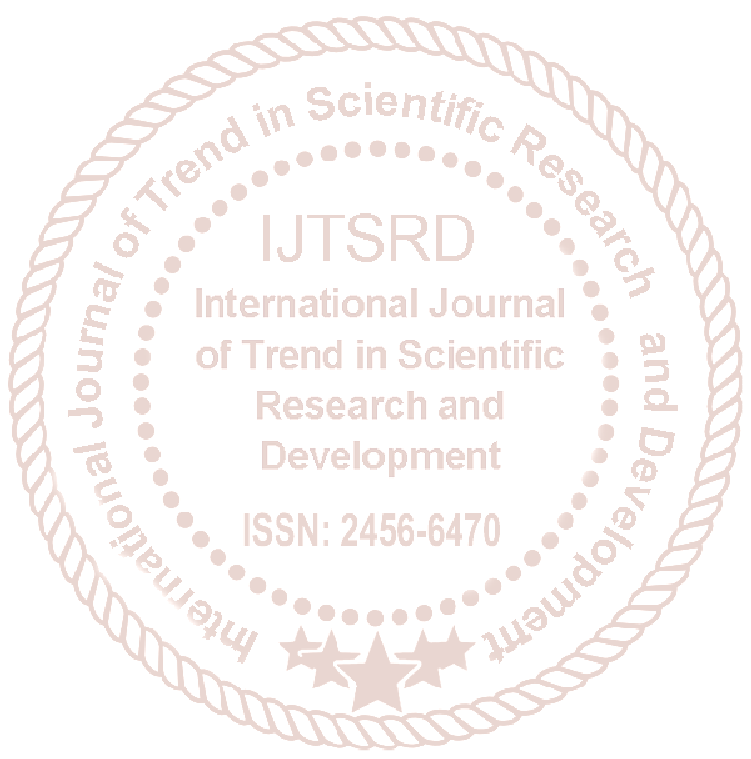

